\title{
Identity Crisis in Jean Rhys’ Wide Sargasso Sea Revisited
}

\author{
Tawfiq Yousef, Reem Abu-Samra \\ Middle East University, Amman, Jordan
}

\begin{abstract}
This paper examines the identity crisis experienced by Antoinette in Jean Rhys' Wide Sargasso Sea (1966) from a predominantly soci-psychological perspective. Since most of the critical attention regarding Wide Sargasso Sea has been devoted to external problems, such as race, gender and colonial politics, this article will concentrate on the psychological relevance of those issues, examining the reasons for the internal conflict and sharp divisions that torment the heroine. It investigates identity crisis faced by the novel's heroine and her struggle to overcome this crisis in a society where woman is triply marginalized by race, class, gender and colonialism. It also traces Antoinette's search and struggle for an independent life and examines the extent to which she succeeds or fails in articulating her identity. Special emphasis will be laid on Erik Erikson's psychological theories of identity crisis and human development. The paper depicts the protagonist's endeavour to overcome the external forces that impact the construction or destruction of her identity. Ultimately, Antoinette reaches a resolution on her own terms, depending on her own personal decision and the surrounding societal and cultural circumstances.
\end{abstract}

Keywords: Rhys, Antoinette, identity crisis, Erikson, socio-psychological approach

\section{Introduction}

Wide Sargasso Sea (1976) is a masterpiece of the British writer Jean Rhys, a mid-20th-century novelist who was born and grew up in the Caribbean island of Dominic abut settled in England from the age of 16. She lived for some time in Europe where she experienced feelings of alienation because of her own personal background and multicultural upbringing. As a white Creole writer living in England, Rhys attempts to capture the issue of being caught between two cultures and never able to identify fully with any of them. Born to a Welsh father and a Creole (white West Indian) mother on the island of Dominica in the West Indies, Rhys was white but not English, West Indian but not black. Wide Sargasso Sea is a postcolonial-feminist novel whose events explore the tragic fate of the female protagonist Antoinette who is a sensitive and lonely young Creole girl whose arranged marriage to an unsympathetic and controlling English man exacerbates her already isolated life and pushes her to fits of violence. Antoinette is caught in the midst of three deeply-rooted ideologies about women that marginalize them on the basis of their class, gender and race. It exposes the life of the Afro-Caribbeans (Jamaicans) who were invaded and occupied by the British as early as 1655 and the relationship between the colonizer and the colonized. In her strenuous attempt to realize her independent identity, Antoinette is subjected to different forms of pressure and oppression exercised upon her by her Jamaican society, the British colonizers and her English patriarchal husband. Eventually, her husband brings her to England and locks her in his attic. Frustrated and illusioned, Antoinette awakes from a horrific dream and

Tawfiq Yousef, Ph.D., Professor, Middle East University.

Reem Abu-Samra, M.A., Postgraduate, Middle East University. 
sets out to burn down the house.

\section{Review of Related Literature}

Since its publication in 1966, Wide Sargasso Sea has been the subject of many critical studies which show very diverse reactions to the novel. Some viewed the novel from a modernist perspective drawing attention to Rhys' extreme economy of form and linking her to other writers from early twentieth century. They emphasized the stream-of-consciousness technique, the psychological side of the characters and the use of multiple narratives. Some critics tried to place the novel within a specifically Caribbean literary tradition while others viewed it from a postmodern perspective. Wide Sargasso Sea has also been examined from feminist, postcolonial, diaspora and identity viewpoints.

One of the most famous of feminist studies is Sandra Gilbert and Susan Gubar's The Madwoman in the Attic: The Woman Writer and the Nineteenth Century Literary Imagination (1979). In their study, the two critics took Antoinette as a symbolic figure, one who represents the way in which women's voices were silenced or suppressed in nineteenth century society. On a more general level, several studies dealing with feminism and identity have been drawn upon for writing this paper. These include Hooks' book Feminism Is for Everybody: Passionate Politics (2000) which is concerned with sex exploitation and oppression. Included also is Ferguson's Race, Gender, Sexuality, and Social Class: Dimensions of Inequality and Identity (2015) which explains how identity is shaped and affected by different factors such as gender, race, class and social environment.

The novel has also been studied from a post-colonial viewpoint. Gayatri Spivak's influential essay, "Three Women's Texts and A Critique of Imperialism" (1985) scrutinizes the relationship between the colonizer and the colonized from a post-colonial perspective. Spivak's analysis of the novel concentrates on the role of language and voice in identity formation. In her article, Silvia Capello (2009) focuses on the importance of voice and cultural identity of the decolonized peoples in the age of post-colonialism. She observes that Wide Sargasso Sea,

...emerges within this huge postcolonial literature where, according to Ashcroft, both a national and a regional consciousness try to assert difference from the imperial center. Such literature subverts the imperial privilege of the "centre" in order to give voice to that "periphery" which has been silent for so long. (Capello, 2009, p. 47)

In her paper "A Postcolonial Reading of Wide Sargasso Sea by Jean Rhys” Neşe Şenel (2014) examines the novel from a post colonialist perspective through studying the notion of "othering" and the related identity problems of the heroine.

There are many studies concentrating on identity in Wide Sargasso Sea. Mona Fayad (1988) explores Antoinette's "hope for the establishment of an autonomous self independent of social expectations (Fayad, 1988, p. 437). Stephanie Coartney (2010) discusses the issue of identity crisis for Antoinette as a typical Creole woman. She argues that "this question plagues Antoinette while she struggles to develop her own identity in the face of cultural and racial rejection". Raja Sharma (2013) explains that Antoinette is a Creole who belongs neither to the white Europeans nor to the black Jamaicans. The study also explores themes related to identity such as assimilation and racial inequality. Nibras Kadhim (2011) examines how Antoinette the heroine of Rhys' novel Wide Sargasso Sea reflects the same sense of exile and marginality the author experienced. El Quardi (2013) attempts to justify the inability of Rhys to create an identity for her character Antoinette even 
though she started with the intention of giving identity to the mad woman in the attic in Charlotte Bronte's novel Jane Eyre. Akram AL-Deek (2016) explains how the novel reflects Rhys' alienation and reveals the three ways in which she feels displaced: as a female marginalized by her male-dominated society, as a Creole of mixed European and black descent, and as an individual displaced from her homeland.

Though most of the studies dealing with identity in this novel tend to adopt a traditional approach, this study will utilize Erik Erikson's socio-psychological theories about identity. In his books, Erikson raises questions about both identity and identity crisis. He stresses that he uses the word crisis in a developmental sense, and claims that an identity crisis is a normal and necessary part of human life. For Erikson, an identity is not static; it is in constant change. In Identity: Youth \& Crisis (1968), he presents eight stages of psychosocial development that build on one another. Erikson proposes a lifespan model of development, suggesting that there is still plenty of room for continued growth and development throughout one's life. Erikson puts a great deal of emphasis on the adolescent period, maintaining it is a crucial stage for developing a person's identity. The outcome of this maturation process is a wide and integrated set of life skills and abilities that function together within the autonomous individual. The focus of Erikson's theory is how children socialize and how this affects their sense of self. These stages will be drawn upon in the subsequent discussion of the question of Antoinette's identity crisis in Wide Sargasso Sea. According to Erikson, the ego develops as it successfully resolves crises that are primarily social in nature. These crises involve establishing a sense of trust in others and developing a sense of identity in society as will be explained later.

\section{Discussion}

Jean Rhys' Wide Sargasso Sea (1966) has been the object of several ethnic, racial, postcolonial and feminist critical readings. Taking those interpretations into account, this paper attempts to shift the focus to the relevance of the socio-psychological questions of racial, parental, colonial and social oppression on the novel's protagonist Antoinette. In this paper we intend to investigate the manifestations of the crisis of identity in Jean Rhys' Wide Sargasso Sea in light of the traditional approaches and in accordance with the socio-psychological approach based on Erik Erikson's theories of identity and identity crisis. Identity crisis has been defined as "a psychosocial state or condition of disorientation and role confusion occurring especially in adolescents as a result of conflicting internal and external experiences, pressures, and expectations and often producing acute anxiety" (American Heritage Dictionary, 2016). It is a personal psychosocial conflict especially in adolescence that involves confusion about one's social role and often a sense of loss of continuity to one's personality. Utilizing the techniques and methods of postcolonialism, feminism and socio-psychosocial theories, the study explores the supportive and encouraging external forces as contrasted with the undermining and discouraging forces in the heroine's long and arduous search for an individual and independent identity. Our analysis will be carried out in light of various theories including race and ethnicity, feminism and postcolonialism with special reference to Erikson's theories of identity and identity crisis.

In Rhys' highly acclaimed novel Wide Sargasso Sea, we notice that Antoinette suffers while she struggles to develop her own identity in the face of social, cultural and racial rejection. Several factors contribute to the crisis of identity that Antoinette faces. In her thesis, El Quardi (2013) studies the fragmentation of Antoinette's identity and shows how ethnicity, gender, social class and status form the basic constituents or dynamics of identity development. She states: 
Antoinette has a fragmentary identity that is constructed through various constituents; these being her race and ethnicity (Creole), her gender (a woman), a post-colonized, and also because of shifting class and status. All these constituents or dynamics help to the understanding of Antoinette's identity (first to the creation of her identity, and then to the process of her identity destruction). (El Quardi, 2013, p. 23)

\section{Race/Ethnicity}

An important factor that leads to the fragmentation of Antoinette's identity and her identity crisis is concerned with race/ethnicity. Antoinette is a white Creole, a woman of mixed Black and European ancestry. After the Emancipation Act 1833 under which Britain outlawed slavery in all its colonies, the suppressed hatred between blacks and whites was released and increased. As a result, Antoinette's childhood has been replete with racial violence, discrimination, anxiety, poverty and fear. All these problems affected her desire to construct her own identity or her independent self and eventually led to the definite destruction of her identity.

As a white Creole in the West Island of Jamaica, Antoinette suffers a confusion of identity and individual existence. She is caught in the middle between the purely white people and the black people without belonging to either race. The black people consider her a hybrid that they look down upon while the British colonizers consider her an alien or an outsider. This leaves Antoinette caught between two cultures and never able to identify fully with any one. Antoinette becomes the "other" who is unable to claim the English identity as her own, nor can she break from the complications of her ethnic background to create an independent self. As Creoles, Antoinette and her mother Anette are maligned by both the black Caribbeans and the white Europeans. Though the Creoles are taught to consider England as home, they are labeled as inferior colonials but they are racially privileged in relation to the Africans. This results in creating a sharp conflict between the white and black population of the West Indies. Antoinette is scorned by both white and black cultures and is thus forced to see herself as "Other" without being able to consider herself as part of these two prevailing ethnic and cultural groups. As Kadhim observes, "She [Antoinette] is, therefore, doubly exiled on her island home and her mother country, having no place to truly belong" (Kadhim, 2011, p. 592). It is basically this sense of belonging to neither culture that brings about Antoinette's identity crisis and finally becomes one of the factors that drive Antoinette into madness.

Antoinette' identity crisis occurs at an early stage of her life. Using her friendship with Tia, her only childhood friend, as a means of knowing herself Antoinette begins to gauge her ethnic and cultural identity. Being black, Tia shows Antoinette the extent to which black people don't like her and her Creole family. Intending to torment her friend, Tia calls Antoinette a "white nigger", a hybrid who does not belong to any specific race (Rhys, 1997, p. 64). Tia's insolent behaviour with her childhood friend shows how much racism is controlling her behavior and her treatment of her Creole friend. Tia refers to Antoinette as poor and dirty; she also tries to underestimate her by cheating on her and by taking her clothes. Antoinette is looking for a place which she loves and to which she belongs. She is also anxious to have a trustworthy friend who would make her feel more secure and might help in the construction of her identity. After the house of Antoinette's father was set on fire, Antoinette tried to run toward Tia hoping to stay with her and find a sense of comfort with her presumed friend. Antoinette is looking for someone to be identified with so that she can feel at home. Antoinette recalls the house she used to live in before it was set on fire and compares it to the Garden of Eden. She says: "Our garden was large and beautiful as that garden in the bible- the tree of life grew there" (Rhys, 1997, p. 6). The island is all that she knows, and she is desperate to identify with it through Tia, her only friend. Antoinette feels that she and Tia have shared the same experiences on this island and so she should have the 
same rights as Tia to consider the island as her homeland from which she derives her identity. She wants to be a part of something, and so she clings to the hope of Tia being like her. This desire manifests itself most strikingly when Antoinette looks directly at Tia as if she were looking into a mirror where she can see a reflection of herself. Of course, her illusions are shattered when Tia throws the stone in her face, breaking the mirror image and leading Antoinette to the realization that she does not belong and that she is not like Tia (Rhys, 1997, pp. 24, 84-85).

Antoinette's struggle for her identity, her belonging and her existence began when she was just a little child where she could not define her own self properly. She was marginalized not only for being of a mixed blood but also for being a female and for being the colonized object as will be explained later. Antoinette is born in the midst of racial conflict. She is the daughter of a white Creole woman and an English slave owner in Jamaica. Her family is hated by the locals who consider it as a family of colonizers. Antoinette is also excluded on the basis of her mother's Creole origin; and so she is rejected by both the black and white population of the island. As Kadhim (2011) explains, “The black community doesn't accept her because she is white. At the same time, she doesn't fit into the world of the whites who consider those of mixed races as inferior to themselves" (p. 591). As a white Creole, Antoinette becomes a double outsider: "white nigger" for the Europeans and "white cockroach" for the blacks (Kadhim, 2011, p. 592). As Antoinette wistfully explains to her husband in the novel:

...a white cockroach. That's me. That's what they [the blacks] call all of us who were here before their own people in Africa sold them to the slave traders. And I've heard English women call us white niggers. ... I often wonder who I am and where is my country and where do I belong and why was I ever born at all. (Rhys, 1997, p. 64)

\section{Feminism/Postcolonialism}

Another factor affecting Antoinette's identity crisis is her gender and her shifting social class and status. Since early childhood, Antoinette has been desperately trying to fit herself into her Caribbean society. Antoinette is a sensitive and lonely young Creole girl who grows up with neither her mother's love nor her peers' companionship. By the time she was supposed to construct an identity of her own away from the values and expectations of others, she gets married to Rochester who becomes an obstacle in the way to an independent self. Rochester is the unnamed white Englishman whom we know only by Jane Eyre's (1847) Rochester, particularly by his biased, racist and repulsively gendered descriptions of his wife Bertha, the Antoinette of Wide Sargasso Sea. Antoinette's unnamed husband is a representative of both colonial and patriarchal systems. Though Rhys tries to humanize the marginalized protagonist Antoinette by giving her a voice to speak out about her own suffering and to express her own feelings, her husband endeavours to suppress her attempts and to deprive her from her right to speak or to have her own independent cultural and social identity.

Antoinette's ill-timed, badly-motivated and ominous marriage makes her suffer from a role confusion or identity crisis because her husband is attempting all the time to eliminate her and her own sense of identity. Antoinette is faced with a crucial decision in her life and on her way to achieving her long-time desired sense of identity. If she decides to fight against the obstacles that are presented through her husband and begins to find a way out to self-realization, she might succeed in resolving her identity crisis and ultimately begin an intimate relationship with the people she loves. Antoinette does not do that; instead, she decides to be submissive and passive; she never fights her husband or thinks of leaving him. 
Initially, the marriage of Antoinette's mother to Mr. Mason, the wealthy Englishman, creates hopes inside Antoinette for solving her identity crisis by inspiring into her the feeling of having a protective family that will make her feel more secure. Their desire to have a better life forces them to imitate the English society in order to indulge into their world. They even start eating their food as they find that this way is the only one for them to choose an identity that distinguishes them from others. In other words, Antoinette and her mother try to imitate the colonizer and to find comfort in adapting their modes of behavior as well as their lifestyle. In postcolonial terms, this behavior can be called "mimicry" to use Bhabha's phrase in his book The Location of Culture (1994). We can see that when Antoinette begins to eat English food in the English way: "We ate English food now, beef and mutton, pies and puddings. I was glad to be like an English girl but I missed the taste of Christophine's cooking” (Rhys, 1997, p. 17). However, this feeling does not solve Antoinette's identity problem. Her sense of her "hybridity" still persists when Antoinette and her mother view themselves as Creole women who neither belong to the Europeans nor to the Jamaicans. They are half way between the two identities, not knowing what to choose as a fixed representation of their identity.

Antoinette's identity crisis reaches its peak with her marriage that has been arranged by her stepfather Mr. Mason and his son Rochester. Before, she used to find hope in her home and her friend Christophine, but now, and with this marriage, the hope is diminishing. Antoinette's husband is shown as a representative of the patriarchal society and the colonial powers. With the appearance of Rochester and his domineering character, the oppression, discrimination and marginalization practiced on Antoinette are magnified. Rochester never gives support to her but tries to eliminate her identity and her presence. His harsh and inhumane treatment of her diminishes any hope for her of ever becoming an independent woman. Rochester has not married her out of love but for money and he never hesitates to keep her under his full control as a colonizer and as a patriarchal man who makes her feel lost. As El Quardi observes: "From her marriage, we can see a withdrawing Antoinette, instead of being given a self. Her identity becomes to fade progressively, until she disappears at the end of the novel" (El Quardi, 2013, p. 30).

Rochester's sexual abuse of his wife makes Antoinette an inferior human being and increases her crisis of identity. Viewed in light of traditional gender roles as explained by Lois Tyson (2006, p. 85), we can see how Antoinette is forced to follow a traditional gender role as an inferior, weak, emotional human being who is unable to take central decisions, while her husband is cast as a superior, strong and rational being. Changing his wife's name into Bertha, Rochester starts treating her as an object and considers her as his property. Rochester is always trying to eliminate her identity and prevent her from taking any central decision in her life. He treats Antoinette as Bertha, not Antoinette. Though Antoinette got married in order to prove herself, it turns out that she is doing exactly the opposite and losing what has remained of hope to get an independent self.

In postcolonial terms and particularly in light of Edward Said's Orientalism (1978), we can notice the "othering" attitude of Rochester when he considers his wife to be the "other" for he is the "subject", the superior Western colonizer, while his wife represents the inferior Creole colonized "object". The decisive negation of Antoinette's identity or existence is further enhanced by the oppression exercised by Rochester on her. Under the colonial hegemony of her husband who is actually a symbol of colonization, Antoinette is colonized into a slave figure and thus loses her identity. Becoming more aware of her need for an identity of her own, Antoinette finally tells Rochester not to call her Bertha: 
Bertha is not my name. You are trying to make me into someone else, calling me by another name... I loved this place and you have made it into a place I hate... I used to think that if everything else went out of my life I would still have this, and now you have spoilt it... I hate it now like I hate you and before I die I will show you how much I hate you. (Rhys, 1997, p. 94)

The above impassioned speech indicates that Antoinette is gradually moving, though slowly, towards achieving a kind of epiphany or realization of what is going on and of her need for an independent self and an identity of her own. When Rochester talks to Antoinette about justice, she simply replies: "There is no justice" (Rhys, 1997, p. 94). Antoinette feels disappointed and reacts strongly: "She smashed another bottle against the wall and stood with the broken glass in her hand and murder in her eyes" (Rhys, 1997, p. 95). Rochester announces that Antoinette has become his own property and now he is planning to take her, against her will, to live in England where he simply locks her in the attic as an attempt to eliminate her from existence. In her new residence in England, Antoinette feels that she lives in darkness to the extent that she cannot recognize herself in a looking-glass which can give her a sense of identity and a recognizable independent self: "I saw Antoinette drifting out of the window with her scents, her pretty clothes and her looking-glass... there is no looking-glass here and I don't know what I am like now" (Rhys, 1997, p. 117). Antoinette doesn't even believe that this is England; it is not how she imagined the place to be: "They tell me I am in England but I don't believe them" (Rhys, 1997, p. 117). This feeling brings Antoinette's identity crisis to a head, where she recognizes herself and sees everything around her dark, vague and even destroyed.

\section{Erikson's Theories of Identity and Identity Crisis}

Antoinette's difficulties in constructing an identity of her own, her submissive character from the beginning till the end, and the series of struggles she undergoes can be perceived from Erikson's socio-psychosocial theories of identity and identity crisis. According to Erikson, the first step $\left(0-1 \frac{1}{2}\right)$ in a child's development is Trust vs. Mistrust, where the baby develops a sense of trust towards it caregivers or a sense of mistrust if he or she finds them to be unreliable. The second step $\left(1 \frac{1}{2}-3\right)$ is Autonomy vs. Shame and Doubt. In this stage, success leads to autonomy, failure to shame and doubt. In the novel, these two stages remain vague and almost unrevealed due to the fact that our knowledge of such events depends on what the narrator Antoinette can see and narrate. We know that Antoinette's father died when she was young. Due to the natives' hatred and discrimination against the whites, Antoinette's childhood was filled with loneliness, poverty, anxiety and fear. After their house was destroyed and her young brother died in the fire set by the blacks, her mother became crazy. Antoinette cannot be happy as she is seriously affected by her family's problematic racial, social and cultural background.

The third stage of a child's development (3-5) is Initiative vs. Guilt where the child explores its surroundings, trying to make plans and build dreams. It is around this stage that we first get a clear glimpse of Antoinette's early development, precisely when she is at a convent school and among her playmates. Being the child of an English ex-slave master and the daughter of a Creole mother, Antoinette is bound to face an identity crisis, given the difficult circumstances that her racial and ethnic backgrounds entail. According to Erikson, around age three and continuing to age five, children assert themselves more frequently. During this period the primary feature involves the child regularly interacting with other children at school. Children begin to plan activities, make up games, and initiate activities with others. If given this opportunity, children develop a sense of initiative, and feel secure in their ability to lead others and make decisions (McLeod, 2013). Conversely, if 
this tendency is repressed, children develop a sense of guilt. A healthy balance between initiative and guilt is important. Success in this stage will lead to the virtue of purpose. Antoinette is brought up by unsympathetic and unloving parents who do not care much about their child. Every time Antoinette asks a question or to start a conversation, she is rebuffed by her mother. Annette harshly turns down her daughter's questions about the past, dismissing every issue concerning it by saying: "all that is long ago" (Rhys, 1997, p. 60). Consequently, Antoinette senses her inability to track down her origins, either through history or through a family. This realization complicates her search for identity, especially at a time in life when her sense of selfhood is still vague and undecided. Things worsen later on when other external forces conspire against Antoinette's search for identity driving the extremes of her already conflictual personality even further asunder.

Antoinette feels deprived of the love she needs and so she finds herself alienated and unsettled. She is in dire need for anyone who can inspire in her some feelings of security and protection especially because she does not have any stable or helpful familial background; she was neglected by her family and her mother in particular. Antoinette's mother Annette does not have an endearing relationship with her daughter. She dislikes her daughter because, as Antoinette explains, her mother is ashamed of her desire to associate herself with the black Caribbeans. Explaining how Antoinette was seeking attachment to objects, places and the black people around her, Dibelkova (2013) points out that this behaviour was part of her attempt to simply define herself among all people around her. She also states that this endeavour came as a result of not receiving love and sympathy from her mother: "It is because of having an unloving mother that Antoinette searches for love among the black people. Annette doesn't help her daughter to identify with herself, and yet forces her to accept the white identity" (Dibelkova, 2013, p. 25).

When her relationship with her mother bogs down, Antoinette turns to Christophine, Anette's servant and Antoinette's nurse, as a substitute. Christine seems to be a supportive force in Antoinette's life. For Antoinette, Christophine represents one who is comfortable with her racial identity. She, therefore, enhances Antoinette's longing to identify with black Caribbean people and culture. Christophine is one of those people who bring a sense of comfort and security to Antoinette who refers to Christophine as an extraordinary woman: "Her songs were not like Jamaican songs, and she was not like the other women" (Rhys, 1997, p. 7). Christophine provides support and protection to Antoinette as a child and as an adult, and in this way she helps her in feeling stronger and more able to construct her own identity. When she leaves, Christophine's absence makes Antoinette feel afraid and insecure about everything around her as she needs her support and the maternal care that all girls in her age need:

I left a light on the chair by my bed and waited for Christophine, for I liked to see her last thing. But she didn't come, and as the candle burned down, the safe peaceful feeling left me. I wished I had a big Cuban dog to lie by my bed and protect me. (Rhys, 1997, p. 19)

The fourth step in a child's psychological development is reached approximately as the child enters school ( 5 years) and lasts until 12 years of age. Here, the child begins comparing itself with others, and meets demands. These trends lead to industry or inferiority. As a 3-5 year old child and until she is about 12 years of age, Antoinette has been living in a very hostile social milieu coming first place from her postcolonial and her ethnic background. According to Erikson, Children at the age of 5 to 12 years begin to develop greater relations with their peer group, an activity that will become a major source of the child's self-esteem. The child now feels the need to win approval by demonstrating specific competencies that are valued by society, and begins to develop 
a sense of pride in its accomplishments. If children are encouraged and reinforced for their initiative, they begin to feel industrious and confident in their ability to achieve goals. If this initiative is not encouraged or restricted by parents or teacher, then the child begins to feel inferior, doubting his/her own abilities and therefore may not reach his or her potential. Success in this stage will lead to the virtue of competence.

Applying these notions to Antoinette, we find that she has not much choice in establishing relations with other children. Antoinette's childhood shows her positioned between the white and black communities. She has affinities with certain black characters such as Tia and Christophine, but cannot fully identify with them. She is white, brought up with a set of values based on superiority and dominance but she longs to be affiliated with the blacks. At the water pool, Tia betrays Antoinette by taking her pennies and stealing her clothes. Antoinette remains naïve as a result of her childhood isolation and an externally-imposed sense of inferiority. Though Tia treats her maliciously, Antoinette continues to be friends with her not only because of her naiveté but also because Tia was perhaps the only child she could find and call a friend. Antoinette is greatly frustrated and deeply disappointed when the only friend she had turned against her. Tia's offhand and impudent treatment of her presumed friend might be attributed to the fact they belong to different races, colors and cultures. Tia is a black native and Antoinette is a white Creole. Antoinette comes from a family of slave-owners hated by the black community. Antoinette and Tia are shown incapable of being friends after all. Nevertheless, for Antoinette, Tia represents the image of someone who is closely affiliated with the island and the black community in a way that Antoinette much desires but cannot achieve. Despite Tia's hurling insults and stones at her friend, Antoinette continues to see Tia as her reflection or looking-glass, an act that shows that Tia is an important force in Antoinette's life.

Identity versus Confusion is the fifth and perhaps the most crucial stage of Erik Erikson's theory of socio-psychosocial development. This stage occurs during adolescence between the ages of approximately 12 to 18. During this stage, adolescents explore their independence and develop a sense of self. They face a developmental conflict that must be resolved to successfully develop and attain their goals. This conflict is centered on developing a personal identity. Successfully completing this stage leads to a strong sense of self that will remain throughout life. According to Erikson, during adolescence (age 12 to 18 years), the transition from childhood to adulthood, the individual wants to belong to a society to fit in. It is during this stage that the adolescent will re-examine his/her identity and try to find out exactly who he or she is. Success in this stage will lead to the virtue of "fidelity" which involves being able to commit one's self to others on the basis of accepting others, even when there may be ideological differences. During this period, adolescents explore possibilities and begin to form their own identity based upon the outcome of their explorations. Failure to establish a sense of identity within society can lead to role confusion which involves individuals not being sure about themselves or their place in society, to a sense of inferiority and to a feeling of unhappiness (McLeod, 2013).

Applying Erikson's theory, we find that Antoinette is becoming increasingly desperate in search for social acceptance, moving between attempting to fit herself into first the role of a Caribbean native and second that of a white English girl. As an adolescent, Antoinette is keen on the notion of possessing a socially acceptable identity in the face of cultural and racial rejection. Viewed as a hybrid descending from English and Caribbean origins, Antoinette realizes that she is rejected by both white and black cultures of which she is composed. Antoinette's desperate desire to belong is clearly manifested in her persistence to associate herself with the dark-skinned girl Tia and the black servant Christophine. Such an attitude alarms Antoinette's mother who has already considered herself to be part of the white English community and who has been engaged to the 
Englishman Mr. Mason. For some time after she becomes Mr. Mason's stepdaughter, Antoinette continues to assert her blackness and to dissociate herself from the white patriarchal system personified in the character of Mr. Mason.

Intimacy versus Isolation is the sixth stage of Erik Erikson's theory of socio-psychosocial development. Occurring during young adulthood between the ages of approximately 19-40, this period marks the individual's concentration on forming intimate, loving relationships with other people. In this stage, adults begin to share their life and experiences more intimately with others. They explore relationships leading toward longer term commitments with someone other than a family member. Successful completion of this stage can lead to comfortable relationships and a sense of commitment, safety, and care within a positive relationship. Avoiding intimacy, fearing commitment and constructive relationships can lead to isolation, loneliness, and sometimes depression. Success in this stage will lead to the virtue of love. A closer look at the Intimacy versus Isolation sage reveals that the major question asked at this level is: Will the individual be loved or will he/she be alone? Consequently, the most important event in this stage is the attempt to establish some committed, permanent romantic and social relationships with other people. Such relationships are often romantic in nature, but may as well contain some intimate social relationships characterized by closeness, honesty and love.

While Erikson's socio-psychological stages are often presented as a series of neatly defined, sequential steps, it is important to remember that each stage contributes to the next. Erikson believed that having a fully formed sense of self established during the identity versus confusion stage, is essential to being able to form intimate relationships. People who have failed to successfully establish intimate relationships are more likely to suffer emotional isolation, loneliness, and depression. After her mother's marriage to Mr. Mason, Antoinette, prompted by her mother and encouraged by her mother's marriage, continues her attempts to gain acceptance among the white community in addition to her earlier attempts to be associated with the native blacks. Urged by her mother and Mr. Mason, Antoinette finally accepts to be married to Rochester and begins to show her increasing love for him. Her general behaviour and lifestyle reveal a predilection for English cultural characteristics and social values such as showing respect for her husband despite his unfriendly treatment of her. She even resorts to her friend Christophine in an attempt to find a way to make Rochester love and accept her through the obeah potion. Antoinette's behaviour indicates that she is now willing to be part of the white English culture and thereby gain a definite identity. Nevertheless, and in a really surprising manner, Rochester embarks on a dubious course of exercising the greatest possible destructive influence on his wife with a view to eliminating her identity calling her strange names such as temptress, witch, doll, hysteric and displaying his strong desire to annul her identity and negate her right to independent selfhood. Antoinette's attempt to establish a meaningful and intimate relationship with her partner has proved to be a total failure with dire consequences. She tries hard to salvage her relationship with her husband on whom she had already pinned great hopes for solving her identity crisis. With the failure of the love potion which she secured with the help of her friend Christophe in order to exercise some influence on her husband to love her, Antoinette is left alone to face her crisis of identity. As Coartney (2010) observes: "When the potion ultimately fails to produce the desired effects, Antoinette is forced to recognize her non-whiteness as well as her non-blackness".

By large, Antoinette's failure to gain her independent and recognized identify is caused by external, not internal, factors. Antoinette has done her utmost to share her life with others and to establish intimate relationships with potential companions and friends but she has been rejected by the racial and cultural stereotypes of her apathetic society. The restrictions imposed on her by the black society of which she is a part 
and the harmful stereotyping of the colonizers with whom she is affiliated are the main reasons of Antoinette's inability to assimilate and achieve her independent selfhood. In the face of this insurmountable opposition coming from both the colonizer and the colonized, Antoinette puts up tough, though futile, resistance to gain her true identity. Rejected and forced into a second class citizen by the native black community on the island, Antoinette is disappointed and feels she is an outcast on the island which she cannot claim to be her homeland even though she knew no other place. As she later tells Rochester, "I loved [the island] because I had nothing else to love" (Rhys, 1997, p. 78). Disdained, oppressed and subjugated by the English colonizers, Antoinette is also made to realize that she is still the victim of harmful colonialism and ruthless patriarchy. The attitudes of both sides on the island prevent Antoinette from feeling accepted by members of her white social group and prohibit her from identifying herself with the native blacks. Caught between a rock and a hard place and faced with this double rejection, Antoinette faces a problem of identity crisis which threatens to diminish her hopes of ever developing a sense of identity. Though Stephanie Coartney (2010) claims that "Antoinette finally forms a secure sense of self at the end of the novel, thus freeing her from the restrictive labels and cruel rejection she has been forced to endure," it is obvious that Antoinette has become the victim of patriarchy and colonization and a harsh, mixed society that leaves no room for Creole women such as Antoinette of ever living their life freely or achieving a real sense of identity. Antoinette is now labeled the same way her mother had been, a lunatic. She has now reached a conclusion where she has despaired of ever succeeding in achieving an identity in such a class-ridden, racial and patriarchal society. All that is left to her is to find a solution of a sort.

Antoinette chooses death as a way of resolving her problem. There are several interpretations of her act at the end. At the end of the novel, we can notice Antoinette burning down the house. Some interpreters view this particular act as a destruction of her identity while others view it as a construction of her identity. Whether this ending of her life is a defeat or a triumph depends on the perspective we look at it. On first looking at the matter, this can be easily recognized as a definite defeat. Looking more closely and in light of a feminist perspective, we can consider it as a moment of triumph. Unable to achieve her goal of having an independent identity because of the various factors conspiring against her, Antoinette realizes that by ending her life, she can do what she likes. Her last deed is setting Thornfield on fire, and with this she ends a story of long suffering. As El Quardi (2013) observes:

...the freedom that she [Antoinette] aimed at took place at the end of the novel; however, freedom could only be achieved through disappearance, to get rid of all the imprisonments from which she suffered. When she dreams of burning Thornfield house, she is thereby liberating herself. (p. 37)

Perhaps Antoinette prefers to die as an attempt to build an imaginary world for herself where she can be with the ones she really loves like Christophine and away from her unloving patriarchal husband in order to go to a place where she feels loved, recognized and defined. Throughout the novel, Antoinette couldn't build a world of her own or gain a recognizable identity. Instead, she ends up locked in the dark attic in Thornfield as a result of her failure to fight against the external forces that try to oppress her and eliminate her identity altogether.

\section{Conclusion}

As a child, Antoinette is rejected by her parents and thrust into a hostile world that is not ready to embrace her. There are no signs of healthy parent-child relationships in the novel. All external factors including like race, 
gender, colonialism, diaspora and cultural stereotyping conspire to create an unstable and fragmented identity for the novel's protagonist leaving her to struggle alone with a daunting question: "Who am I?" Though Antoinette undergoes a taunting experience of internal suffering and conflict, her crisis of identity is caused by the relentless external forces engulfing her and finally affecting her sense of existence and their beliefs in herself as independent entity. Consequently, Antoinette becomes triply marginalized for her gender, class and race. Antoinette is discriminated against by her societies and her husband just for the fact that they are women who are considered less important and inferior to men according to the traditional gender roles and the patriarchal norms that have been internalized and taken for granted in her society. Being a Creole of a mixed blood or a hybrid, Antoinette feels alienated and exiled in her community, feeling that she neither belongs to the black Jamaicans nor to the white Europeans. The effect of colonization is actually felt in the novel and acts a deterrent to Antoinette's interaction with her society. Deprived of her inherited property by her patriarchal husband, Antoinette becomes helpless and in bad need for the financial support of her husband. She is left with hardly any opportunity to gain her identity or change her financial and social status until she finally decides to take a fatal decision that would end her life and put an end to her suffering and failure. The struggle for a true identity and an independent self reaches its resolution for Antoinette who chooses death as the best solution to get herself out of her misery by burning the place where she is imprisoned. In one sense, Antoinette somehow reaches her own identity but on her own terms and through her own and not others' decision.

\section{References}

Al-Deek, A. (2016). Writing displacement: Representation of home and identity in post-colonial fction. London: Palgrave Macmillan.

American Heritage Dictionary of the English Language (4th ed.). Retrieved 2016 from http://www.dictionary.com/browse/divers Bhabha, H. K. (1994). The location of culture. New York \& London: Routledge.

Capello, S. (2009). Postcolonial discourse in Wide Sargasso Sea: Creole discourse vs. European discourse, periphery vs. center, and marginalized people vs. white supremacy. Journal of Caribbean Literatures, 6(1), 47-57.

Coartney, S. (2010). Identity crisis for the Creole woman: A search for self in Wide Sargasso Sea. Retrieved January 26, 2010 from http:/faculty.mckendree.edu/scholars/ winter2008/coartney.htm

Dibelkova, V. (2013). Multiple identities in Wide Sargasso Sea by Jean Rhys (Unpublished thesis, University of Pardubice, Pardubice, the Czech Republic).

El Quardi, S. (2013). The impossibility of creating identity in Jean Rhys' Wide Sargasso Sea (M.A. thesis, University of La Roja, Argentina).

Erikson, E. H. (1968). Identity: Youth and crisis. New York: W.W. Norton.

Erikson, E. H. (2014). Erikson's stages of pychological development. In Wikipedia. Retrieved from http://en.wikipedia.org/wiki/Erikson's_stages_of_psychosocial_development

Fayad, M. (1988). Unquiet ghosts: The struggle for representation in Jean Rhys' Wide Sargasso Sea. Modern Fiction Studies, 34(3), 437-452.

Ferguson, S. J. (Ed.). (2015). Race, gender, sexuality, and social class: Dimensions of inequality and identity (2nd ed.). Singapore: SAGE Publications.

Gilbert, S., \& Gubar, S. (1979). Madwoman in the attic: A Study of women and the literary imagination in the nineteenth century. New Haven: Yale University Press.

Hooks, B. (2000). Feminism is for everybody: Passionate politics. London: Pluto Press.

Kadhim, N. J. (2011). Double exile: Jean Rhys’ Wide Sargasso Sea. Journal of College Of Education for Women, 22(3), 589-605.

McLeod, S. A. (2013). Erik Erikson. Retrieved from http://www.simplypsychology.org/Erik-Erikson.html

Rhys, J. (1997). Wide Sargasso Sea. A. Smith, (Ed.). London: Penguin Books.

Şenel, N. (2014). A postcolonial reading of Wide Sargasso Sea by Jean Rhys. Journal of Language and Literature Education, 11, $38-45$. 
Sharma, R. (2013). Ready reference treatise: Wide Sargasso Sea. eBook kopen. e-Journal of New World Sciences Academy, 2011, $5(4)$.

Spivak, G. (1985). Three women's texts and a critique of imperialism. Critical Inquiry, 12(1), 243-261.

Tyson, L. (2006). Critical theory today: A user friendly guide (2nd ed.). New York: Routledge. 